\title{
Systematic hardness measurements on single crystals and polycrystalline blanks of cesium halides
}

\author{
D B SIRDESHMUKH*, P GEETA KRISHNA and $K$ G SUBHADRA \\ Department of Physics, Kakatiya University, Warangal 506 009, India
}

MS received 1 June 2001; revised 29 March 2002

\begin{abstract}
Vickers and knoop hardness measurements were carried out on CsBr and CsI single crystals. Polycrystalline blanks of $\mathrm{CsCl}, \mathrm{CsBr}$ and $\mathrm{CsI}$ were prepared by melting and characterized by $\mathrm{X}$-ray diffraction. Vickers hardness measurements were carried out on these blanks. The hardness values were correlated with the lattice constant and the Schottky defect formation energy.
\end{abstract}

Keywords. Vickers hardness; knoop hardness; cesium halides.

\section{Introduction}

Among the alkali halides, cesium chloride, cesium bromide and cesium iodide crystallize in the well known $\mathrm{CsCl}$ structure (space group $P m 3 m$ ). These crystals are useful as infrared optical materials (Harshaw Catalogue 1967), as radiation detectors (Optovac Catalogue 1993) and in nuclear fuel container technology (Fullam 1972).

While there is an enormous amount of work on the crystal growth of alkali halides with $\mathrm{NaCl}$ structure, work on cesium halide single crystals is limited. Single crystals are commercially supplied by Harshaw and Optovac at prohibitive cost. Single crystal growth in academic research centres is rare, perhaps, because among the alkali halides, the cesium halides are the most expensive. In the case of $\mathrm{CsCl}$, single crystal growth is hampered by a structural transition just below the melting point (Harshaw Catalogue 1967).

For many applications and property measurements, polycrystalline blanks can be used in place of single crystals. The fabrication of aggregates is much simpler than growth of single crystals and, further, smaller quantities of raw material are required. Studies of polycrystalline aggregates of $\mathrm{NaCl}$ and $\mathrm{KCl}$ are reported by Dobson and Wilman (1962a), Subramanyam (1962), Armington et al (1973) and Leuenberger et al (1981). With the exception of an electron diffraction study of $\mathrm{CsCl}$ (Dobson and Wilman 1962b), there is no report of any study on the polycrystalline aggregates of the cesium halides.

Although there is considerable information on several physical properties of cesium halides, information on their hardness is sketchy. No report could be traced on the hardness of $\mathrm{CsCl}$. Values of hardness of $\mathrm{CsBr}$ and $\mathrm{CsI}$ are quoted without any details in the Harshaw Catalogue (1967).

\footnotetext{
*Author for correspondence
}

The purpose of the present communication is two-fold: (i) to report on the fabrication and characterization of polycrystalline blanks of cesium halides and (ii) to report results of systematic hardness measurements on single crystals as well as polycrystalline blanks of cesium halides.

\section{Experimental}

\subsection{Materials}

The single crystals used in these studies are shown in figure 1. The $\mathrm{CsBr}$ and $\mathrm{CsI}(\mathrm{H})$ crystals were grown and supplied by Harshaw. They are in the form of cubes bound by the (100) faces. The CsI(M) crystal was grown at the Institute of Crystallography, Moscow; it is a plate with (100) faces, cut out from a boule.

Polycrystalline blanks were prepared by melting about $2 \mathrm{~g}$ of the material in a minifurnace and cooling the melt slowly. The cooling rate was $10^{\circ} \mathrm{C} / \mathrm{h}$ for the first $5 \mathrm{~h}$ and $50^{\circ} \mathrm{C} / \mathrm{h}$ till the ingot reached ambient temperature. Further details are given in an earlier paper (Srinivas et al 1999). The resulting blanks were annealed at about $400^{\circ} \mathrm{C}$ for $8-10 \mathrm{~h}$ to minimize strains. The blanks fabricated by us (figure 2) are homogeneous and optically clear.

$\mathrm{X}$-ray back reflection photographs of the blanks were recorded on a flat-plate camera using $\mathrm{Cu}$ radiation (figure 3). Although no measurements have been made on these photographs, a study of their appearance itself yields useful information. These photographs do not show Laue spots characteristic of single crystals. Instead they show powder lines with varying features. The photograph for $\mathrm{CsCl}$ shows spotty lines indicating presence of coarse grains. The highest angle (521) reflection is also spotty but is discontinuous indicating some preferred orientation. In the case of $\mathrm{CsBr}$, the (521) reflection is a com- 

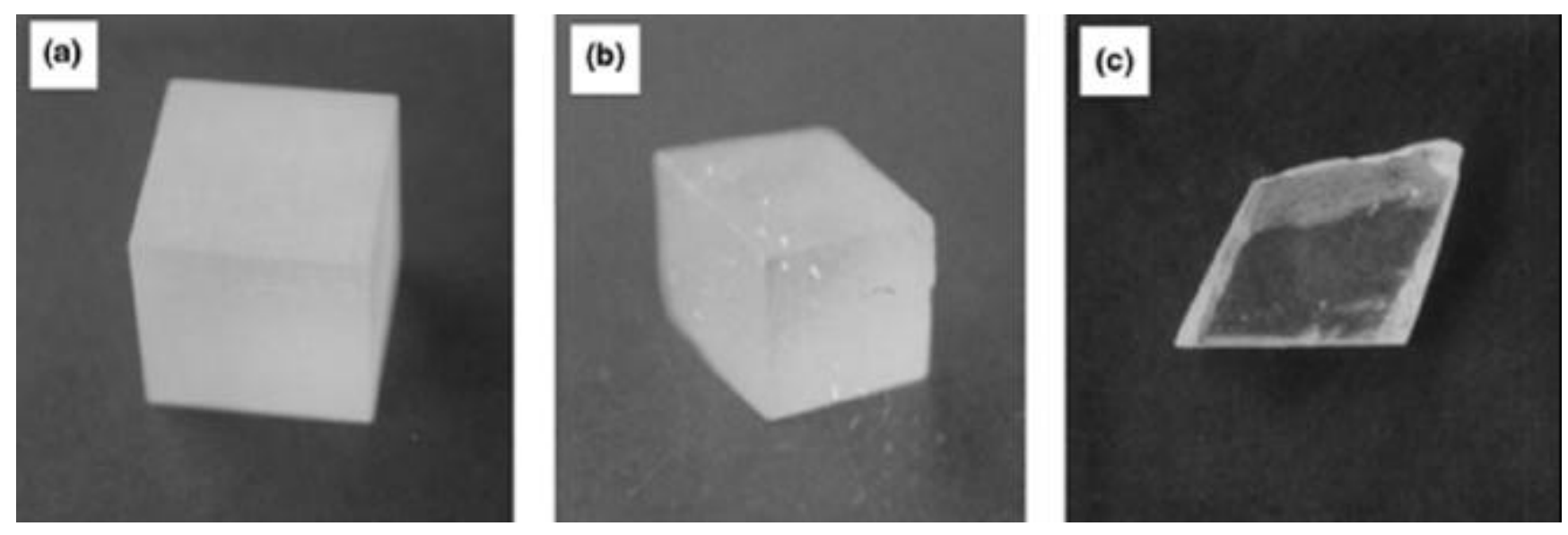

Figure 1. Photographs of single crystals of (a) CsBr, (b) CsI (H) and (c) CsI (M).

pletely continuous line indicating fine grains. Superposed over the (521) line are a few intense spots suggesting a slight degree of preferred orientation. In CsI, again, the (521) reflection is a continuous powder line suggesting existence of very fine grains. There are intense spots superposed over the line indicating preferred orientation.

From the optical clarity of the blanks and the features of the X-ray photographs, it may be concluded that the simple method of melting followed by slow cooling results in homogeneous and essentially polycrystalline blanks made up of fine or coarse grains with a slight degree of preferred orientation. The existence of preferred orientation was taken care of, while making hardness measurements $(\S 2 \cdot 2)$.

\subsection{Microhardness measurements}

Microhardness measurements were made with the help of a Leitz-Wetzlar Miniload Hardness Tester. Using a Vickers diamond pyramidal indenter, the Vickers hardness $\left(H_{\mathrm{V}}\right)$ was calculated from the relation

$$
H_{\mathrm{V}}=(1854 \cdot 4) P / d^{2} \text {, }
$$

where $P$ is the applied load and $d$ the length of the diagonal of the indentation impression. With $P$ in $\mathrm{g}$ and $d$ in $\mu \mathrm{m}, H_{\mathrm{V}}$ turns out to be in $\mathrm{kg} / \mathrm{mm}^{2}$. Hardness measurements were made at several loads in the range 5-100 g. The values of $H_{\mathrm{V}}$ calculated from (1) show a load dependence. The final values of $H_{\mathrm{V}}$ are corrected for this load dependence following a detailed discussion given in an earlier paper from this laboratory (Sirdeshmukh et al 2000). In the case of polycrystalline blanks, to take care of any preferred orientation, measurements were made for different orientations of the sample surface with respect to the indenter axis and the mean value was taken. For measurement of knoop hardness, the Vickers indenter was replaced with a knoop indenter and the knoop hardness, $H_{\mathrm{K}}$, was calculated from the relation

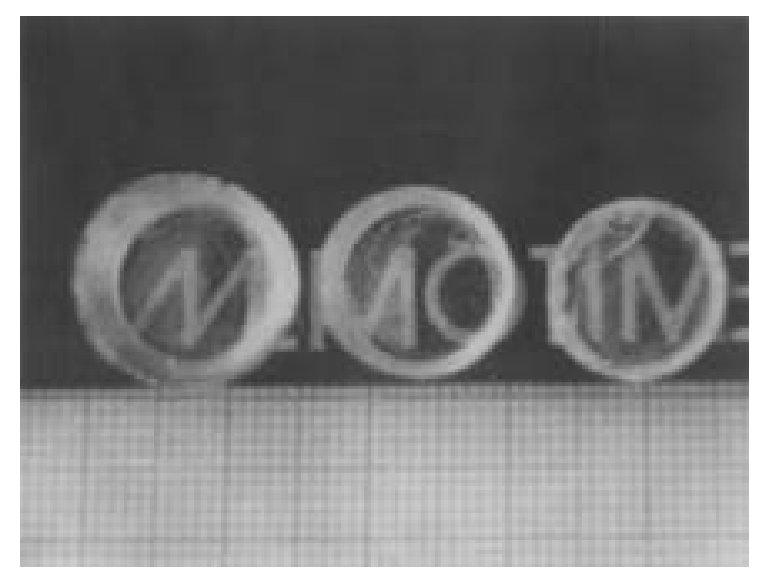

Figure 2. Photographs of polycrystalline blanks of (1 to $r$ ) $\mathrm{CsI}, \mathrm{CsBr}$ and $\mathrm{CsCl}$.

$$
H_{\mathrm{K}}=14500 P / l^{2},
$$

where $P$ is the load and $l$ the length of the long axis of elongated diamond-shaped indentation. Measurements were made by orienting the single crystals such that the $\langle 100\rangle$ and $\langle 110\rangle$ directions were parallel to the long axis of the indenter. This orientation was carried out by mounting the crystal on a circular stage.

By differentiating (1) and inserting the error $\Delta d$, the error in hardness $\left(\Delta H_{\mathrm{V}}\right)$ can be estimated from the relation

$$
\Delta H_{\mathrm{V}}=-2 H_{\mathrm{V}}(\Delta d / d)
$$

with a similar relation for $\Delta H_{\mathrm{K}}$.

\section{Results and discussion}

\subsection{Vickers hardness}

The results of Vickers hardness measurements are given in table 1 . As mentioned in $\S 1$, we could not trace any 
earlier report on the microhardness of $\mathrm{CsCl}$. For $\mathrm{CsBr}$, our values for the single crystal and the polycrystalline blank agree within limits of experimental errors. Further, the
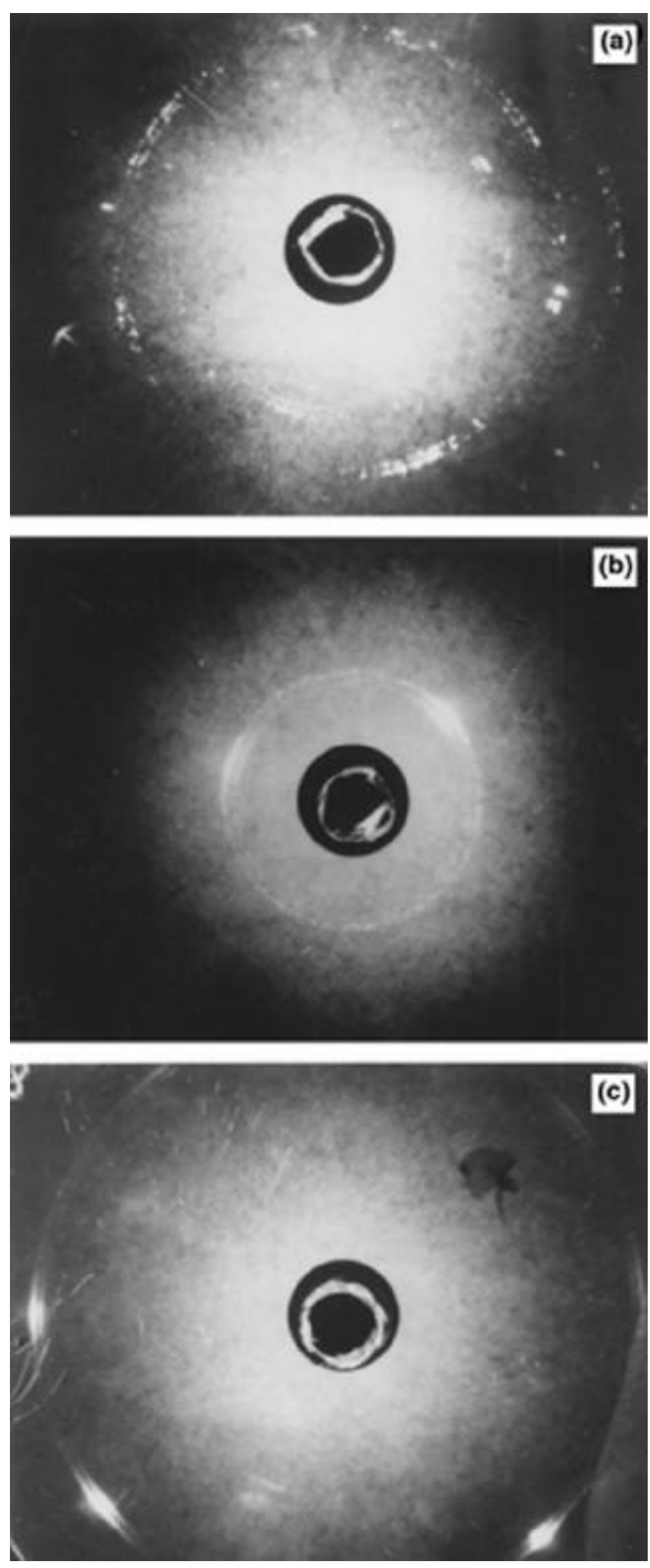

Figure 3. X-ray back reflection photographs of polycrystalline blanks of (a) $\mathrm{CsCl}$, (b) $\mathrm{CsBr}$ and (c) CsI. present values also agree with the value of $19.5 \mathrm{~kg} / \mathrm{mm}^{2}$ quoted in the Harshaw Catalogue (1967). For CsI, the Harshaw catalogue (1967) quotes a value of $20 \mathrm{~kg} / \mathrm{mm}^{2}$. In the present work a value of $12.8 \mathrm{~kg} / \mathrm{mm}^{2}$ has been obtained from measurements on the $\mathrm{CsI}(\mathrm{H})$ single crystal. This is much lower than (almost half) the Harshaw catalogue value. However, our hardness value for $\mathrm{CsI}(\mathrm{H})$ crystal agrees well with our values for $\operatorname{CsI}(\mathrm{M})$ and also for the polycrystalline blank. That CsI is much softer than $\mathrm{CsBr}$ was clear from the sizes of the indentations made on the two crystals at a given load.

Hardness and lattice constant are both related to the strength of the interatomic binding. The stronger the binding, shorter is the lattice constant and larger the hardness. Thus, we expect a correlation between the hardness and lattice constant in a family of related crystals. Smooth plots between hardness and lattice constants were obtained for the alkali halides with $\mathrm{NaCl}$ structure by Thirmal Rao and Sirdeshmukh (1991) and for divalent chalcogenides with $\mathrm{NaCl}$ structure by Sirdeshmukh et al (1995). Recently, Sirdeshmukh et al (2001) obtained a straight line plot between the hardness and lattice constant of rare earth garnets. The lattice constants of cesium halides are given in table 1 . In figure $4 \mathrm{a}$, the hardness values of the three cesium halides are plotted against their lattice constants. All data points lie on a straight line except the data point for the Harshaw Catalogue value for CsI.

Shukla and Bansigir (1976) proposed a model according to which the indentation made during a hardness measurement on an ionic crystal results in the creation of a certain number of Schottky defects. For a crystal with $\mathrm{NaCl}$ structure, they obtained the relation

$$
H_{\mathrm{V}}=206 E_{\mathrm{f}} / r^{3}
$$

where $E_{\mathrm{f}}$ is the energy of formation of a Schottky pair and $r$ the interionic distance. Here $H_{\mathrm{V}}$ is in $\mathrm{kg} / \mathrm{mm}^{2}, E_{\mathrm{f}}$ in $\mathrm{eV}$ and $r$ in $\AA$. The constant in the equation arises out of the work done by the indenter in displacing crystalline matter and the volume per vacancy pair, both of which are dependent on the structure of the crystal. Shukla and Bansigir (1976) obtained a linear plot between $H_{\mathrm{V}}$ and the parameter $E_{\mathrm{f}} / r^{3}$ in accordance with (4). They did not include the cesium halides in their analysis. The model and the equation should be applicable to the alkali halides with $\mathrm{CsCl}$ structure with an appropriate change in the numerical value of the constant in (4). The values of $E_{\mathrm{f}}$ and $r$ are given in table 1 . In figure $4 \mathrm{~b}$, the values of $E_{\mathrm{f}} / r^{3}$ for the cesium halides are plotted against the hardness values. Again, it is observed that all data points are close to a straight line, except the data point for the Harshaw catalogue value for CsI, and follow the equation

$$
H_{\mathrm{V}}=537 E_{\mathrm{f}} / r^{3}
$$

which is similar to (4). 
To conclude, the hardness values for CsI obtained from measurements on three samples agree amongst themselves. Further, our CsI hardness values satisfy two wellestablished empirical relations while the Harshaw value does not. These facts support the present hardness value of CsI as against the much higher value quoted in the Harshaw catalogue. Differences in the hardness values similar to that as observed by the authors for CsI in the present studies exist in the case of $\mathrm{AgCl}$ also, wherein the Harshaw catalogue value is $9.5 \mathrm{~kg} / \mathrm{mm}^{2}$ and two independent measurements (Chin et al 1973; author's unpublished results) yield a value of $5 \mathrm{~kg} / \mathrm{mm}^{2}$. However, these comparisons are limited by the fact that the details of measurements in the case of Harshaw Catalogue values are not available.

\subsection{Knoop hardness}

Knoop hardness measurements were made at the lowest possible load of $5 \mathrm{~g}$. For larger loads, the knoop impression was going beyond the field of view. Due to possible load variation, the knoop hardness value at $5 \mathrm{~g}$ will not be comparable with the load-variation-corrected Vickers value. However, it has been pointed out by Armstrong and Raghuram (1973) and Thirmal Rao et al (1991) that while hardness is load-dependent, the hardness anisotropy is not. Hence only the knoop hardness anisotropy ratio $H_{\mathrm{K}}(100) / H_{\mathrm{K}}(110)$ is given in table 1 . The ratio has values of $\sim 1.4$ for both $\mathrm{CsBr}$ and CsI. It has been observed (Sirdeshmukh and Kishan Rao 1988) that for alkali halides with $\mathrm{NaCl}$ structure, this ratio has a value

Table 1. Values of the Vickers hardness, $H_{\mathrm{V}}$, knoop hardness anisotropy ratio $\left[H_{\mathrm{K}}(100) /\right.$ $\left.H_{\mathrm{K}}(110)\right]$, lattice constant $(a)$, interionic distance $(r)$ and the formation energy for Schottky defects $\left(E_{\mathrm{f}}\right)$.

\begin{tabular}{|c|c|c|c|c|c|c|c|}
\hline \multirow[b]{2}{*}{ Material } & & \multicolumn{2}{|c|}{$H_{\mathrm{V}}\left(\mathrm{kg} / \mathrm{mm}^{2}\right)$} & \multirow[b]{2}{*}{$\begin{array}{l}H_{\mathrm{K}}(100) / \\
H_{\mathrm{K}}(110)\end{array}$} & \multirow[b]{2}{*}{$a^{\mathrm{b}}(\AA)$} & \multirow[b]{2}{*}{$r^{\mathrm{b}}(\AA)$} & \multirow[b]{2}{*}{$E_{\mathrm{f}}^{\mathrm{c}}(\mathrm{eV})$} \\
\hline & & $\begin{array}{l}\text { Single } \\
\text { crystal }\end{array}$ & $\begin{array}{l}\text { Polycrystalline } \\
\text { blanks }\end{array}$ & & & & \\
\hline $\mathrm{CsCl}$ & & - & $21 \cdot 8 \pm 2 \cdot 0$ & - & $4 \cdot 123$ & $3 \cdot 571$ & $1 \cdot 860$ \\
\hline $\mathrm{CsBr}$ & & $\begin{array}{c}19 \cdot 0 \pm 2 \cdot 0 \\
19 \cdot 5^{\mathrm{a}}\end{array}$ & $18 \cdot 5 \pm 2 \cdot 0$ & 1.47 & $4 \cdot 286$ & $3 \cdot 712$ & 1.744 \\
\hline CsI & $\begin{array}{l}\text { (H) } \\
\text { (M) }\end{array}$ & $\begin{array}{c}12 \cdot 8 \pm 1 \cdot 0 \\
11 \cdot 8 \\
20 \cdot 0^{\mathrm{a}}\end{array}$ & $12 \cdot 2 \pm 1 \cdot 0$ & 1.44 & $4 \cdot 567$ & $3 \cdot 955$ & 1.407 \\
\hline
\end{tabular}

${ }^{a}$ Harshaw catalogue (1967); ${ }^{b}$ Wyckoff (1965); ${ }^{c}$ Murthy and Murti (1971).
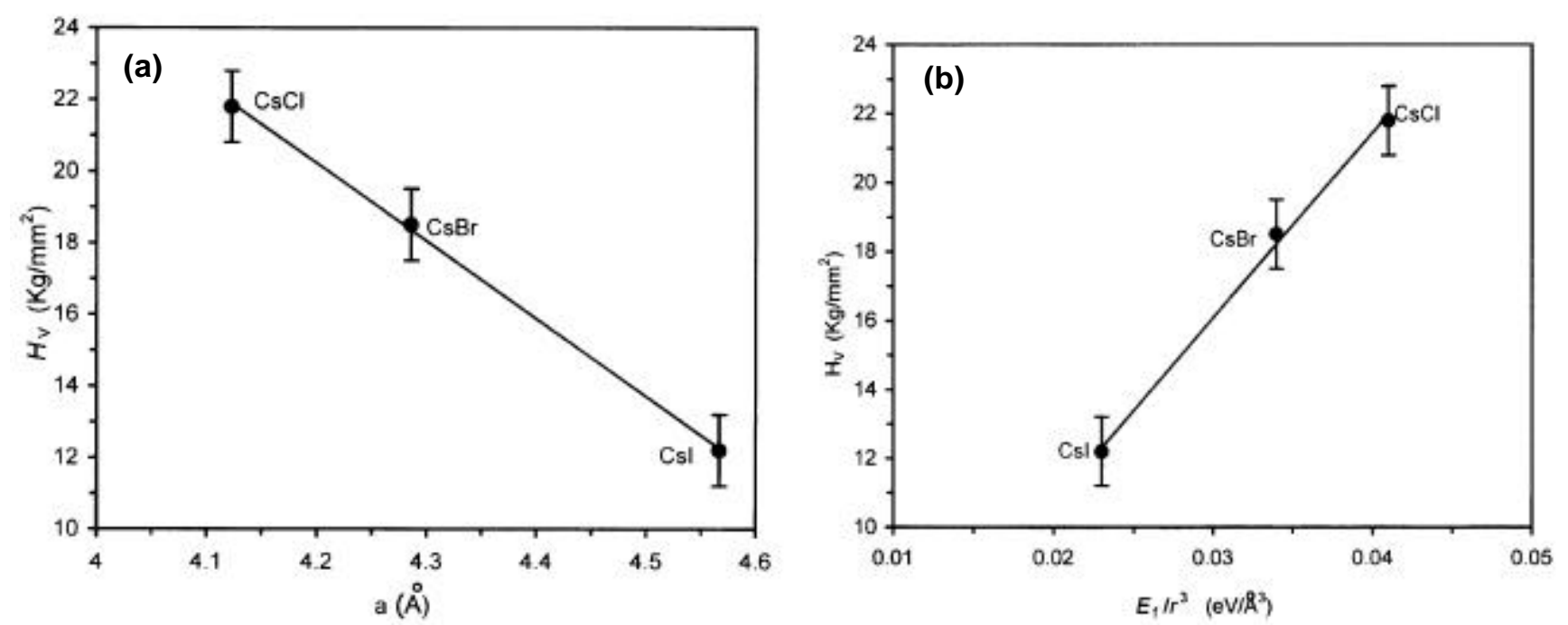

Figure 4. Plots of (a) microhardness $\left(H_{\mathrm{V}}\right)$ vs lattice constant $(a)$ and $(\mathbf{b}) H_{\mathrm{V}}$ vs the parameter $E_{\mathrm{f}} / r^{3}$. 
$>1$. The alkali halides with $\mathrm{CsCl}$ structure also show the same trend.

\section{Conclusions}

Polycrystalline blanks of cesium halides have been prepared by melting followed by slow cooling. These blanks are optically clear. X-ray diffraction photographs show that they are homogeneous and nearly-fully polycrystalline. Vickers microhardness measurements on polycrystalline blanks and on single crystals show that the former have mechanical strength comparable with the latter. Vickers microhardness of the cesium halides correlates linearly with the lattice constant and the parameter $E_{\mathrm{f}} / r^{3}$ where $E_{\mathrm{f}}$ is the formation energy of a Schottky pair and $r$ the interionic distance. The knoop hardness anisotropy $H_{\mathrm{K}}(100) / H_{\mathrm{K}}(110)$ is about 1.4 for both $\mathrm{CsBr}$ and CsI.

\section{Acknowledgements}

Grateful thanks are due to D E Schuele, Michelson Professor, Case Western Reserve University, for keeping the expensive $\mathrm{CsBr}$ and CsI crystals at our disposal. The CsI crystal grown in Moscow was a gift from the late Dr $\mathrm{R}$ Thyagarajan. The referee is gratefully acknowledged for many valuable suggestions. (DBS) thanks the University Grants Commission for financial support in the form of an Emeritus fellowship.

\section{References}

Armington A F, Posen H and Lipson H 1973 J. Electronic Mater. 2127
Armstrong R and Raghuram A C 1973 in The science of hardness testing and its research applications (Ohio: American Society of Testing Metals)

Chin G Y, Van Uitert L G, Green M L and Zydzik K G 1973 J. Mater. Sci. 81421

Dobson P S and Wilman H 1962a Acta Crystallogr. 14 1275

Dobson P S and Wilman H 1962b Acta Crystallogr. 15 556

Fullam H T 1972 Mater. Res. Bull. 7289

Harshaw Optical Crystals Catalogue 1967 (Cleveland, Ohio: Harshaw Chemical Co.)

Leuenberger H, Heisteni E N and Sucker H 1981 Chem-IngTech. $\mathbf{5 3} 43$

Murthy C S N and Murti Y V G S 1971 J. Phys. C: Solid State Phys. 41108

Optovac Optical Crystal Handbook 1993 (Brookfield: Optovac)

Shukla M and Bansigir K G 1976 J. Phys. D9 L49

Sirdeshmukh D B and Kishan Rao K 1988 J. Mater. Sci. Lett. 7 567

Sirdeshmukh D B, Subhadra K G, Kishan Rao K and Thirmal Rao T 1995 Cryst. Res. Technol. 30861

Sirdeshmukh D B, Subhadra K G and Kishan Rao K 2000 Bull. Mater. Sci. 23147

Sirdeshmukh D B, Sirdeshmukh L, Subhadra K G, Kishan Rao K and Bal Laxman S 2001 Bull. Mater. Sci. 24469

Srinivas K, Thirmal Rao T, Subhadra K G and Sirdeshmukh D B 1999 Phys. Edu. 16273

Subramanyam S V 1962 Acustica 1237

Thirmal Rao T and Sirdeshmukh D B 1991 Cryst. Res. Technol. 26 K53

Thirmal Rao T, Kishan Rao K and Sirdeshmukh D B 1991 Cryst. Res. Technol. 26 K189

Wyckoff R W G 1965 Crystal structures (New York: Interscience Publishers) Vol. I 